Old Dominion University ODU Digital Commons

Medical Diagnostics \& Translational Sciences

Faculty Publications

Medical Diagnostics and Translational Sciences

10-1989

\title{
Embryonic Chicken Fibroblast Collagen Binding Proteins: Distribution, Role in Substratum Adhesion, and Relationship to Integrins
}

Roy C. Ogle

Old Dominion University, rogle@odu.edu

A. Jeannette Potts

Marchall Yacoe

Charles D. Little

Follow this and additional works at: https://digitalcommons.odu.edu/medicaldiagnostics_fac_pubs

Part of the Animal Structures Commons, Cell Biology Commons, Cells Commons, Cellular and Molecular Physiology Commons, Developmental Biology Commons, and the Embryonic Structures Commons

\section{Repository Citation}

Ogle, Roy C.; Potts, A. Jeannette; Yacoe, Marchall; and Little, Charles D., "Embryonic Chicken Fibroblast Collagen Binding Proteins: Distribution, Role in Substratum Adhesion, and Relationship to Integrins" (1989). Medical Diagnostics \& Translational Sciences Faculty Publications. 4.

https://digitalcommons.odu.edu/medicaldiagnostics_fac_pubs/4

\section{Original Publication Citation}

Ogle, R.C., Potts, A.J., Yacoe, M., \& Little, C.D. (1989). Embryonic chicken fibroblast collagen binding proteins: Distribution, role in substratum adhesion, and relationship to integrins. Journal of Cell Science, 94(2), 361-369. 


\title{
Embryonic chicken fibroblast collagen binding proteins: distribution, role in substratum adhesion, and relationship to integrins
}

\author{
ROY C. OGLE*, A. JEANNETTE POTTS, MARSHALL YACOE and CHARLES D. LITTLE† \\ Department of Anatomy and Cell Biology, School of Medicine, Box 439, Medical Centre, University of Virginia, Chartottesville, VA 22903, USA \\ - Present address: Department of Anatomy and Cell Biology, Medical University of South Carolina, Charleston, SC 29425, USA \\ † Author for correspondence
}

\section{Summary}

Collagen binding proteins (CBP) are hydrophobic, cell surface polypeptides, isolated by collagen affinity chromatography. Antibodies to CBPs inhibit the attachment of embryonic chicken heart fibro. blasts to native type I collagen fibrils in a dosedependent manner. The CBP antibodies also induce rounding and detachment of cells adherent to a planar substratum. This process of antibodymediated substratum detachment resulted in a clus. tering of CBP and cell-associated extracellular matrix at the cell surface, and the rearrangement of filamentous actin. Other functional studies showed that cells grown within a three-dimensional gel of type I collagen cannot be immunostained at the cell surface with CBP antibodies. However, treatment

of cultures with purified collagenase, unmasks immunoreactive sites and permits strong cell surface immunolabeling. This result suggests that collagen sterically blocks antibody access to CBP. Finally, we show that antibodies to CBP recognize purified avian integrin $\beta$ subunits; and that antibodies to avian integrins recognize a $100000 M_{\mathrm{r}}$ CBP. These data demonstrate that chicken embryonic fibroblasts possess surface polypeptides that mediate adhesion to type I collagen, and suggest that two of these proteins are related to the integrin family.

Key words: collagen, fibroblast, adhesion.

\section{Introduction}

Cells produce, modify and adhere to their surrounding extracellular matrix (Hay, 1984). These cell surface: ECM interactions are dynamic processes mediated by membrane-associated receptors that recognize specific features of extracellular macromolecules. One group of these adhesion molecules, the integrins, has been identified on a variety of cell types from a wide range of invertebrate and vertebrate organisms (Hynes, 1987). The integrins have conserved their structure and function during evolution (Buck and Horwitz, 1987; DeSimone and Hynes, 1988). Most members of the integrin superfamily of receptors, thus far described, bind to RGD peptide sequences in the ECM ligand (Ruoslahti and Pierschbacher, 1986).

The integrins, present on a variety of avian cell types, attach to fibronectin and laminin through an extracellular ligand-binding domain (Tamkun et al. 1986). The receptor spans the plasma membrane and interacts with microfilament bundles through a cytoplasmic domain (Chen et al. 1985; Burridge, 1986; Buck and Horwitz, 1987). Thus, these receptors appear to form a transmembrane linkage between the matrix surrounding the cell and its cytoskeletal network. Regulation of cell morphology and motile activity, processes known to require the participation of the cytoskeleton and the extracellular matrix, occur through the integrated activity of matrix receptors.

Characterization of these matrix receptors has involved the production of antibodies that perturb adhesion to a particular matrix molecule (Greve and Gottlieb, 1982; Neff et al. 1982), or more recently, affinity chromatography with a specific matrix molecule (Pytela et al. 1985; Rubin et al. 1986). The latter technique is useful for identifying receptors with high affinities for their ligand(s). The human fibronectin receptor present on osteosarcoma cells was isolated by affinity chromatography on a fragment of fibronectin containing the cell binding domain (Pytela et al. 1985). This receptor has, therefore, a relatively high affinity for its ligand. Another high-affinity human fibronectin receptor, VLA-5, is present in placental tissue (Hemler et al. 1987). Also present in placental tissue is a low-affinity fibronectin receptor, VLA-3. Identifying and isolating low-affinity ECM receptors is a challenge, since conventional affinity chromatography is not effective.

We previously reported that several embryonic chicken glycoproteins bind to collagen with what appears to be moderate affinity (Ogle and Little, 1989). These glycoproteins, termed collagen binding proteins (CBPs), were bound to a collagen I affinity matrix under low ionic 
strength conditions, and then eluted with moderately high $(0.5 \mathrm{M})$ levels of $\mathrm{NaCl}$. The CBPs possess the characteristics of receptors in that: (1) they are present at the cell surface as evidenced by radioiodination; (2) they are integral membrane proteins, which resist extraction by urea and salt washes; (3) they are hydrophobic; and (4) they contain N-linked carbohydrate (Ogle and Little, 1989). The CBPs appear to be distinct, individual polypeptides, on the basis of differences in apparent electrophoretic mobility on SDS-PAGE and unique antibody staining patterns on cells and tissues. Two of the CBPs are potential members of the integrin receptor family, on the basis of sensitivity to elution from a collagen column with the synthetic peptide sequence GRGDS, and electrophoretic mobilities on reduced and non-reduced SDS-polyacrylamide gels (Ogle and Little, 1989).

In this study we examine the biological properties of the CBPs through the use of polyclonal antisera raised against the $C B P$ complex. In addition, we investigate the potential relationship of CBP 1 and CBP 2 to avian integrins by the use of antibodies that define the chicken fibronectin receptor.

\section{Materials and methods}

\section{Materials}

For biosynthetically labeling CBP, $\left[{ }^{35}\right.$ S $]$ methionine was purchased from Amersham, as was iodine-125 for radioiodination $\left(16.7 \mathrm{mCi}^{125} \mathrm{Img}^{-1}\right.$ ), octyl-beta-D-glycopyranoside (octylglucoside) was purchased from Calbiochem-Behring (La Jolla, $\mathrm{CA}$ ), and ultra-pure urea and ammonium sulfate from Schwarz/ Mann (Cambridge, MA). Immobilon $(0.45 \mu \mathrm{m})$ was from Millipore, and NBD-phallacidin from Molecular Probes, Inc. (Junction City, OR). Monospecific polyclonal antıserum to the $140 \mathrm{~K}\left(\mathrm{~K}=10^{3} M_{\mathrm{r}}\right)$ glycoprotein complex was a gift from $\mathrm{Dr}$ W.-T. Chen, Georgetown University and Dr K. Yamada, NCI. Goat anti-rabbit immunoglobulin $\mathrm{G}$ ( $\mathrm{IgG}$ ) horseradish peroxidase (HRP)-conjugated second antibodies were purchased from Cappel Laboratories. Avian integrins that were purified on a CSAT monoclonal antibody affinity columns (Neff et al. 1982) were generously provided by C. Buck, Wistar Institute, L. Urry and R. Hynes, MIT. Unless otherwise indicated, all other reagents were purchased from Sigma Chemical Co.

\section{Cell culture}

Chick heart fibroblasts (CHF) were prepared from minced hearts dissected from 9-day embryos by treatment with $0.1 \%$ trypsin (Gibco), $0.002 \mathrm{M}-\mathrm{ED}$ TA, $\mathrm{Ca}^{2+}$ and $\mathrm{Mg}^{2+}$ free Hank's balanced salt solution. CHF were plated and grown in highglucose Dulbecco's modified Eagle's medium (DMEM) supplemented with $10 \%$ fetal bovine serum (or in some cases $10 \%$ chicken serum), $100 \mu \mathrm{g} \mathrm{ml}^{-1}$ gentamicin (Gibco) and $0.002 \mathrm{M}$ glutamine in an atmosphere of $10 \% \mathrm{CO}_{2}$. Cells used for experiments were in the third and fourth passage.

\section{Collagen purification}

Type I collagen was purified from adult chicken skin and tendons of 17-day embryos by neutral salt purification (Miller and Rhodes, 1982) with and without pepsin treatment ( $1 \mathrm{mg} \mathrm{ml}^{-1}$ ). Two cycles of neutral $\mathrm{pH}$ salt precipitation were required to remove all contaminating type III collagen. Purity was assessed by SDS-polyacrylamide gel electrophoresis.

\section{Radiolabeling of chick heart fibroblasts}

For radiorodination studies, cultures of $\mathrm{CHF}$ were detached from dishes by treatment with phosphate-buffered saline (PBS) containing $5 \mathrm{~mm}$-EDTA (PBS-EDTA). The cells were washed three times with PBS containing $0.5 \mathrm{mM}-\mathrm{MgCl}_{2}, 0.9 \mathrm{~mm}-\mathrm{CaCl}_{2}$, resuspended at a concentration of $10^{7}$ cells ml $\mathrm{ml}^{-1}$ and iodinated by the lactoperoxidase-glucose oxidase method as described (Schneider et al. 1982). Cells were metabolically labelled with $\left[{ }^{35} \mathrm{~S}\right]$ methionine $\left(100 \mu \mathrm{Ci} \mathrm{ml}^{-1}\right)$ in DMEM (methionine-free) plus $10 \%$ chicken serum. Radiolabelled cells were washed three times with PBS, they lysed in radioimmunoprecipitation buffer $(0.1 \%$ SDS, $1.0 \%$ deoxycholate, $1.0 \%$ Triton X-100, $0.15 \mathrm{M}-$ $\mathrm{NaCl}, 1 \mathrm{~mm}$-phenylmethylsulfonyl fluoride (PMSF), $0.05 \mathrm{M}-$ Tris- $\mathrm{HCl}, \mathrm{pH} 7.6$ ) and the resulting solution was cleared by centrifugation. Affinity-purified CBP antibodies were reacted with the lysate, and the resulting immune complexes were precipitated with protein A-Sepharose and then analyzed by SDS-PAGE.

\section{Purification of collagen binding proteins}

Collagen binding proteins were purified from $\mathrm{CHF}$ plasma membranes as described (Ogle and Little, 1989).

\section{Production and characterization of antibodies}

Polyclonal antibodies to avian CBP were raised in a rabbit using approximately $20 \mu \mathrm{g}$ of CBP (purified by two cycles of collagen affinity chromatography) emulsified in Freund's complete adjuvant. The immunogen was injected into the surgically exposed popliteal lymph nodes of each hind leg (Boudie et al. 1966). The rabbit was boosted with $100 \mu \mathrm{g}$ CBP in incomplete adjuvant by subcutaneous injection at 4-week intervals and bled every 3 weeks after the second injection. Antibodies were affinity purified on CBP (Little and Chen, 1982) or on CBP transferred to nitrocellulose (described below).

Plasma membranes of fourth passage $\mathrm{CHF}$ were solubilized in Laemmlı (1970) sample buffer, separated on a $7.5 \%$ SDS-polyacrylamide slab gel and transferred to nitrocellulose paper $(0.2 \mu \mathrm{m}$, Schleicher and Schuell). Narrow strips were trimmed from the edges, probed with CBP antiserum and developed with goat anti-rabbit HRP-conjugated second antibodies. The position of the immunoreactive bands was determined by aligning the two strips in their original position. Strips corresponding to the migration position of the CBPs were cut from the sheet, blocked with bovine serum albumen (BSA), and used as a solid-phase inmunoadsorbant, for isolating antibodies present in the whole CBP serum. After extensive washing with $\mathrm{PBS}$, bound antibodies were eluted from the paper strips with $0.2 \mathrm{M}$-glycine $/ \mathrm{HCl}, \mathrm{pH} 2.8$. The solution was quickly neutralized with $1.0 \mathrm{M}-\mathrm{Na}_{2} \mathrm{HPO}_{4}$, and then $0.1 \mathrm{mg} \mathrm{ml}^{-1}$ of carrier protein (BSA) was added. The antibody-containing solution was dialyzed against water and lyophilized. Antibodies were reconstitued at approximately $400-500 \mu \mathrm{g} \mathrm{ml}^{-1}$. It should be noted that it is likely that some of the IgG does not survive the purification as functional antibody. This procedure is adapted from a method described by Talian and coworkers (1983).

\section{Inhibition of attachment assay}

A supply of embryonic chicken (11 day) heart fibroblasts in the third passage were frozen in liquid nitrogen; all experiments came from this pool of cells. Collagen substrata were prepared as described (Chen and Little, 1985) in $35 \mathrm{~mm}$ plastic dishes (Falcon Plastics). The CBP antiserum was dialyzed against DMEM (without serum) and filter sterilized $(0.22 \mu \mathrm{m})$. The day prior to an attachment assay, cells were thawed and plated in $100 \mathrm{~mm}$ dishes with DMEM plus $10 \%$ fetal bovine serum 
(FBS). The next day the subconfluent cultures were trypsinized and suspended in DMEM (with and without FBS, similar results were obtained), and the number of cells was determined with a hemocytometer. Cells were adjusted to approximately $3.0 \times 10^{5}$ cells ml ${ }^{-1}$ and $0.5 \mathrm{ml}$ samples were placed in collagencoated dishes along with the appropriate dilution of CBP antibodies, in a $0.5 \mathrm{ml}$ sample. The total volume per $35 \mathrm{~mm}$ dish was $1.0 \mathrm{ml}$. The number of cells in several identical samples were counted with the aid of a hemocytometer to confirm the concentration of the cell suspension. Cultures were incubated in a humidified $\mathrm{CO}_{2}$ incubator for $2 \mathrm{~h}$, then the dish was flooded with $3 \%$ paraformaldehyde and held for photography. The number of cells in the medium, after the $2 \mathrm{~h}$ incubation, was determined and then expressed as the percentage of the total number of cells originally placed in culture. In one set of experiments the CBP was passed over a gelatin-Sepharose column to remove rabbit fibronectin; no differences in the experimental results were noted. Control experiments with preimmune serum were conducted exactly as the CBP anti-serum experiments.

\section{Immunoblots}

The antigen samples were subjected to electrophoresis in $7.5 \%$ SDS-polyacrylamide gels, then transferred to nitrocellulose paper (Schleicher and Schull) or nylon membranes (Immobilon) with an American Bionetics graphite electrode using a 6aminohexanoic acid buffer system. Membranes were blocked with primary antibodies for $1 \mathrm{~h}$ at room temperature, washed and incubated with horseradish peroxidase-conjugated goat anti-rabbit IgG for $1 \mathrm{~h}$ then developed with 1-chloro-4-napthol as a chromogen.

\section{Other methods}

Indirect immunofluorescene staining, microscopy and photography were carried out as described (Little and Chen, 1982). Electrophoresis was performed as described (Laemmli, 1970) and proteins were visualized with Coomassie Blue R-250 or by autoradiography of dried gels exposed to Kodak XAR-5 film employing Dupont Cronex lightning plus intensifying screens.

\section{Results}

\section{Production and characterization of antibodies to $C B P$}

Affinity-purified CBP were used to immunize a rabbit. Immunoprecipitation reactions with antisera from early bleeds showed activity against bands designated CBP 1, 2 and 4 of $M_{\mathrm{r}} 120000,100000$, and 47000 , respectively (Fig. 1). After several boosts the antiserum recognized CBP 3, $M_{\mathrm{r}} 63000$. The migration positions of CBP 1 and 2 , previously shown to be sensitive to GRGDS elution, are similar to the molecular weights of avian integrin subunits (Knudsen et al. 1985; Akiyama et al. 1986; Tamkum et al. 1986; Marcantonio and Hynes, 1988).

\section{Inhibition of adhesion to collagen fibrils by anti-CBP}

Chicken heart fibroblasts (CHF) were assayed for their ability to attach and spread on a substratum of native collagen I fibrils in the presence of increasing amounts of antiserum to CBP. Fig. 2A shows CHF were inhibited from attaching to collagen substrata in a dose-dependent fashion by the CBP antisera. The panel of micrographs (Fig. 2B) shows the progressive inhibition of cellular spreading on native collagen fibrils that occurs concomitantly with the decrease in adhesive activity.

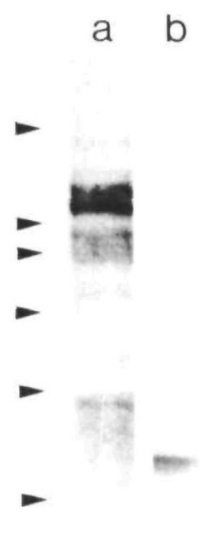

Fig. 1. Antiserum to $C P B$ was used to precipitate reactive bands from a detergent lysate of cells metabolically labeled with $\left[{ }^{35}\right]$ methionine. A prominent band at approximately $120 \mathrm{~K}$ is observed along with bands at $100 \mathrm{~K}$ and $45 \mathrm{~K}$ (lane a). A control immunoprecipitation reaction with non-immune serum (lane $b$ ). The arrowheads indicate the position of molecular weight markers (from the top: 205, 116, 97, 66, $45 \mathrm{~K}$ ) separated on this $7.5 \%$ gel.
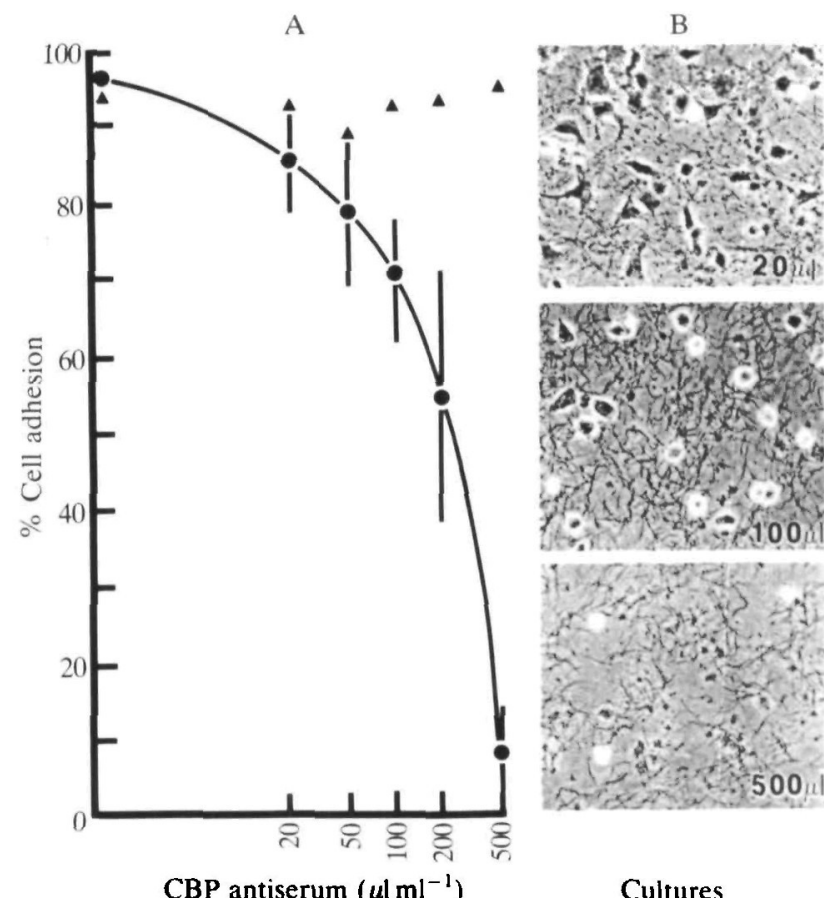

Fig. 2. A. Inhibition of cellular attachment to collagen I fibrils. CHF were incubated with increasing amounts of CBP antiserum (-), which had been dialyzed against DMEM, or dialyzed pre-immune serum $(\boldsymbol{\Delta})$. Attachment was inhibited in a dose-dependent fashion by antibodies against CPBs. B. Phase-contrast images of cell after $2 \mathrm{~h}$ of culture in the dilution of CPB antiserum indicated. Native collagen fibrils are visible. Cells show less spreading in response to increasing amounts of $\mathrm{CPB}$ antibodies. Control (pre-immune) cultures resembled the upper micrograph. 


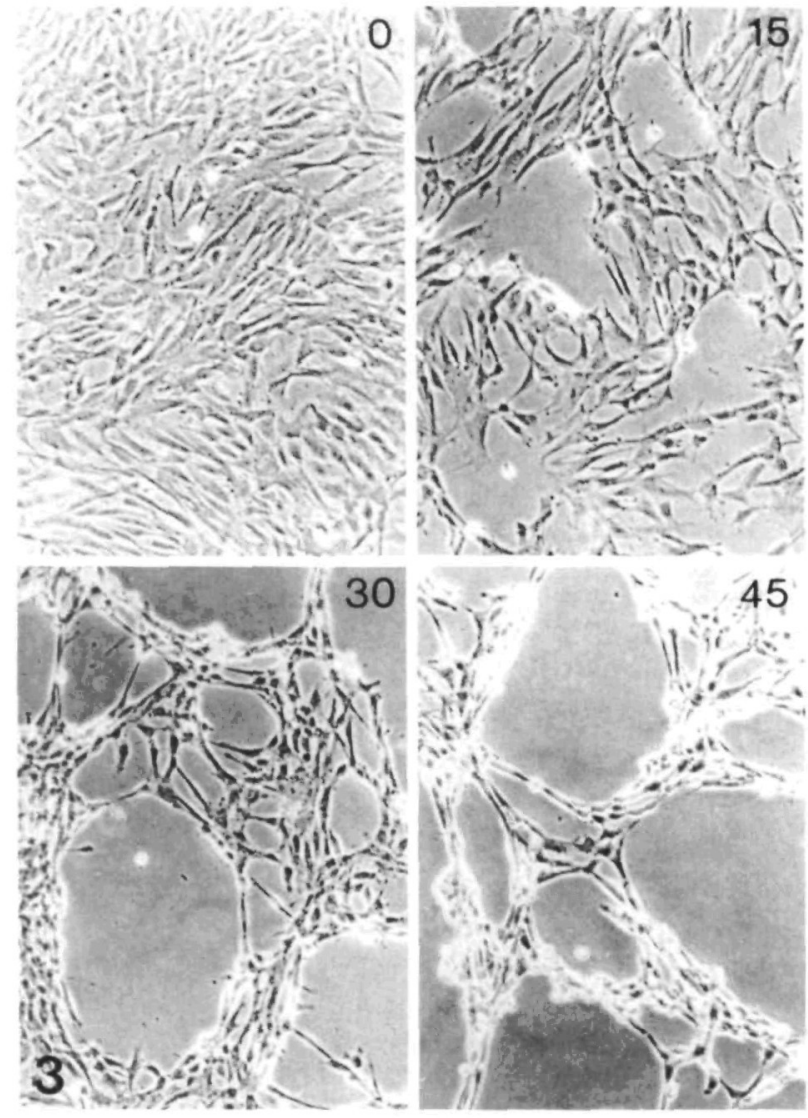

Fig. 3. Progressive release of embryonic chicken heart fibroblasts (CHF) from substratum by antibody treatment. Confluent CHF were incubated in the presence of $5 \%$ antiserum to total CBP and photographed at 15 -min intervals (as shown). Cell-substratum rather than cell-cell adhesion was perturbed most by this treatment. Monospecific antibodies to CBPs 1 and 2 gave identical results (see Fig. 4B). The process could be accelerated by a higher concentration of antiserum.

\section{Release of adherent cells by antibody treatment}

Confluent cultures of $\mathrm{CHF}$ were treated with medium containing $5 \%$ heat-inactivated CBP antiserum or preimmune serum. Over the course of $1 \mathrm{~h}$ cells were observed to become detached from the substratum, to round up and to be released into the medium (Fig. 3). Most cells were released from the plastic or glass substratum prior to detaching from neighbouring cells, suggesting that cell-substrate, rather than cell-cell adhesions were perturbed. Purified monospecific antibodies to CBP 1 and CBP 2 had similar effects on substratum adhesion (see Fig. 4B). Pre-immune antiserum had no discernable effect (data not shown).

Cell cultures undergoing this process of retraction and release were examined for the distribution of $\mathrm{CBP}$, collagen and microfilament bundles. Fig. 4A shows cells examined for the co-distribution of CBP and f-actin. The embryonic fibroblasts were fixed at $15 \mathrm{~min}$ and $60 \mathrm{~min}$ after the addition of CBP antiserum. The immunostaining is intensified at the cell periphery where retraction is occurring. These same areas show a focal concentration of f-actin. Similar cultures were incubated with affinity- purified antibodies to CBP 1 and CBP 2 (Fig. 4B). These specific antibodies caused the retraction and release of most cells, although some cells appeared to resist the antibody effect. In experiments not shown, immunoreactive clumps of collagen $I$ and fibronectin were also drawn into these retraction processes at the cell periphery after the addition of anti-CBP. Eventually, the retraction and rounding process resulted in most of the cells being released completely from the substratum. If these 'released' cells were briefly treated with trypsin $(0.1 \%$ for $15 \mathrm{~s}$ ), they readily became re-attached to a new substratum (data not shown).

\section{Localization of collagen binding proteins on CHF grown in three-dimensional collagen gels}

CHF grown in native three-dimensional type I collagen gels were examined by immunofluorescence. Repeated attempts to immunolabel cells, grown within threedimensional collagen gels with CBP antibodies, ended in failure (Fig. 5B). Positive immunological control experiments with anti-tubulin showed that IgG could diffuse through the gel and not only reach the cell surface, but also enter the cytoplasmic compartment and label microtubules (data not shown; see Tomasek and Hay, 1984). Failure to label the cell surface with CBP antibodies, therefore, was not due to limited movement of $\operatorname{IgG}$ through the collagen gel. Treatment of the cultures with highly purified bacterial collagenase (free of non-collagenous proteolytic activity) hydrolyzed the collagen and rendered CBPs accessible to antibody (Fig. 5D). Furthermore, immunoreactive sites unmasked by the collagenase were distributed evenly over the entire surface of the CHF; including the fine filopodial projections characteristic of fibroblastic cells cultured in three-dimensional collagen gels (Fig. 5C,D).

\section{Distribution of the collagen binding proteins on $\mathrm{CHF}$}

Monospecific affinity antibodies were isolated on individual bands of CBP 1-4 bound to nitrocellulose (see Materials and methods). Immunolocalized studies on embryonic chicken heart fibroblasts revealed that cells labeled independently with antibodies to either CBP 1 or CBP 2 displayed indistinguishable fluorescence staining patterns. Moreover, no differences in the CBP 1 or CBP 2 staining patterns were observed after the cells were made permeable with detergent. Fig. $6 \mathrm{~A}$ and $\mathrm{B}$ shows cells stained with anti-CBP 1, before and after detergent treatment. Cells labeled with antibodies to CBP 3 had sparce clumps of fluorescence; permeabilization resulted in bright perinuclear staining (not shown). Immunostaining for CBP 4 showed an unremarkable diffuse staining (not shown).

\section{Comparison of CBP I with integrin}

Previous work. (Ogle and Little, 1989) suggested biochemical similarities between integrins and CBPs 1 and 2 (e.g. their sensitivity to elution from a collagen-Sepharose column with a synthetic GRGDS peptide). Here we prepared whole lysates from surface radioiodinated cells for analysis by immunoprecipitation in order to compare anti-CBP activity with $140 \mathrm{~K}$, a polyclonal antiserum 

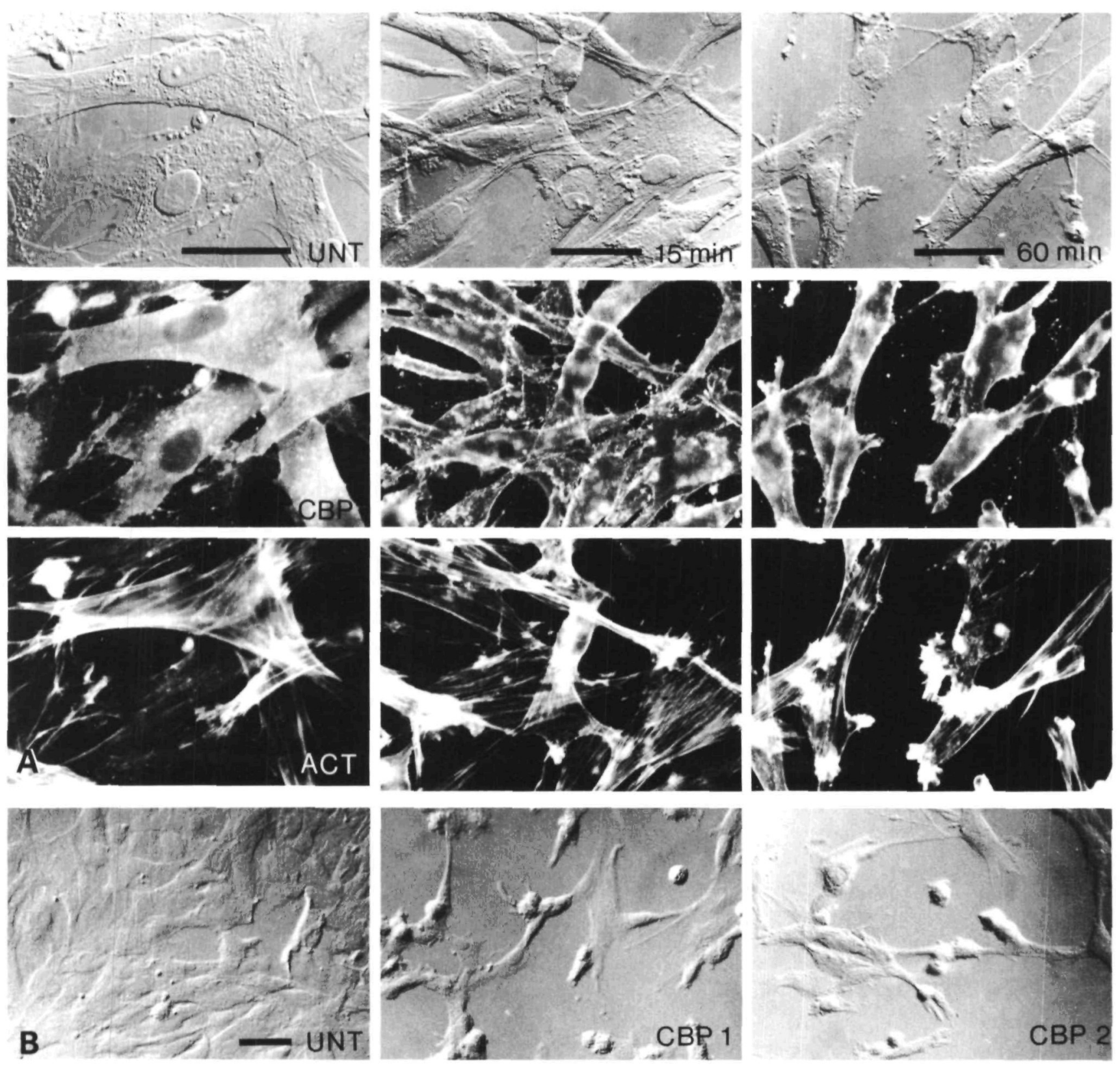

Fig. 4. A. Cells treated with antibodies to CBP as described for Fig. 3 were fixed at $15 \mathrm{~min}$ and $60 \mathrm{~min}$ following addition of antibodies to cultures. The distribution of actin microfilament bundles (ACT) and CBPs were examined by fluorescence microscopy, and compared with untreated cells (UNT). As CBP antibodies cause cells to retract from the substratum, $f$-actin in microfilament bundles is drawn into clusters. These clusters of actin-rich material co-distributed in CPBs at sites that remained unattached to the substratum. Bar, $50 \mu \mathrm{m}$. B. Cells treated with affinity-purified antibodies to CBP 1 and CBP 2 (approximately $200 \mu \mathrm{g} \mathrm{ml}^{-1}$ ) were incubated for $30 \mathrm{~min}$, then fixed for DIC microscopy. Most cells retracted or were released; however, some cells resisted the antibodies, which may be due to the heterogeneous nature of early-passage CHF.

raised against the $\beta$ subunit of the avian fibronectin receptor. Fig. 7A shows that polypeptides immunoreactive with anti-CBP (lanes 1,2 ) or anti-140K (lanes $3,4)$ display remarkably similar electorphoretic mobilities when analyzed by SDS-PAGE; both without disulfide reduction (lanes 1,3 ), and with disulfide reduction (lanes, 2, 4).

The possibility that CBPs 1 and 2 are immunologically related to the integrin family of ECM receptors was tested in two ways (Fig. 7B). First, affinity-purified collagen binding proteins were separated on SDS-polyacrylamide gels, transferred to nylon membranes, and then probed with either CBP antibodies (lane 1) or $140 \mathrm{~K}$ antibodies (lane 2). Second, immunoaffinity-purified avian integrins were prepared using a CSAT antibody column. This material was also separated by SDS-PAGE, electroblotted, and probed with the CBP antibodies or $140 \mathrm{~K}$ antibodies (lanes 3 and 4 ). Collagen binding proteins 


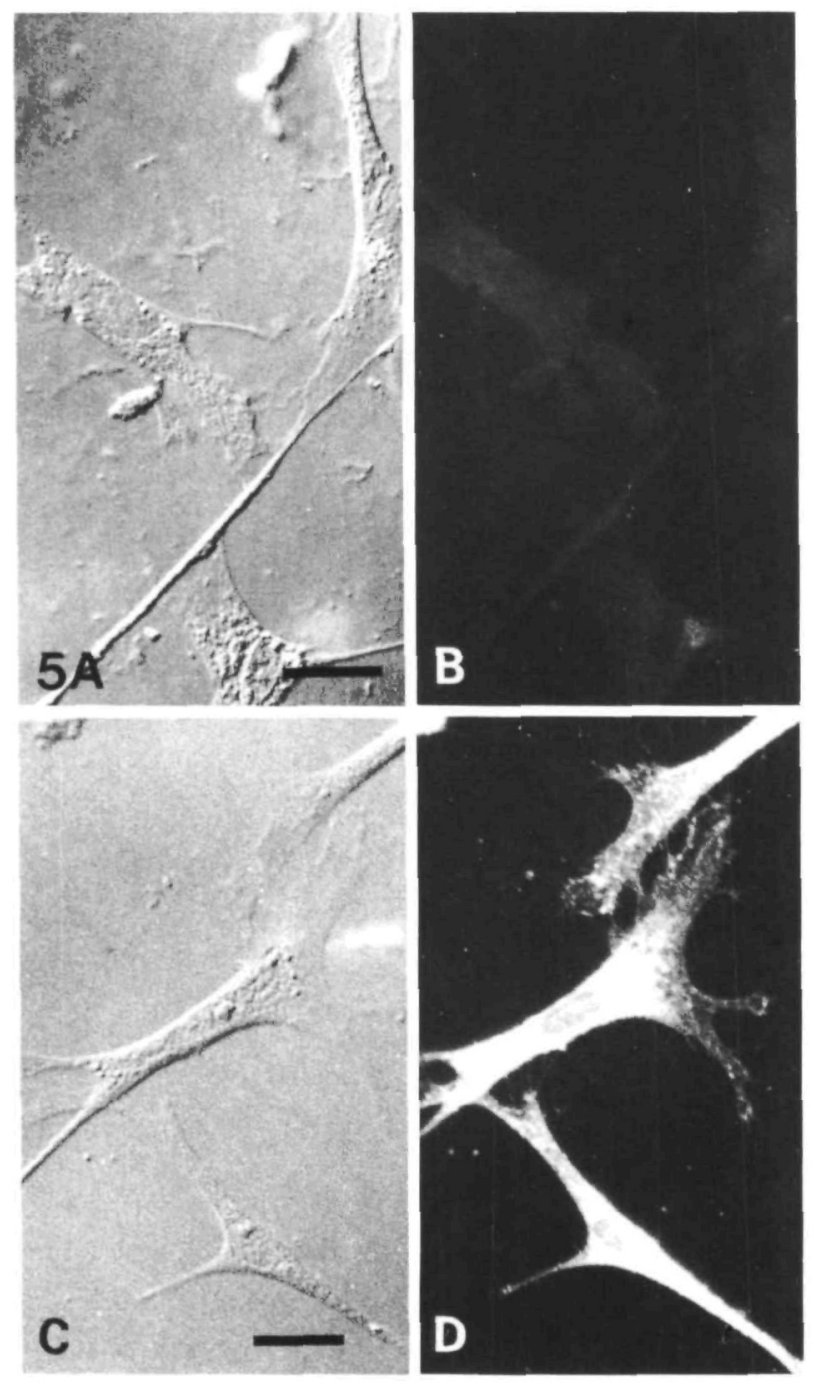

Fig. 5. Distribution of CBPs on CHF grown within threedimensional collagen gels. Cells were cultured within gels of rat tail collagen as described in Materials and methods, fixed and immunostained with antibodies to each individual CBP and total CBPs. Surface staining was not detectable on cells within the collagen gel $(A, B)$. However, when the collagen gels were hydrolyzed with purified bacterial collagenase, a strong surface staining was evident (C,D). Immunostaining to CBP serum is shown, antibodies to CBP 1 and CBP 2 showed similar immunostaining properties under these conditions (data not shown). Bar, $20 \mu \mathrm{m}$

show an immunoreactive polypeptide band with an apparent molecular weight of 100000 when probed with either anti-CBP (lane 1) or anti-140K (lane 2). Similarly, CSAT-purified avian integrins show immunoreactive bands at approximately 100000 when reacted with antiCBP (lane 3) or anti-140K (lane 4). Antibodies to CBP detected higher molecular weight complexes when reacted with collagen binding proteins (lane 1), and 140K antibodies detected high molecular weight complexes within the CSAT-purified integrin fraction (lane 4 ). This higher molecular weight material is possibly $\beta$ dimers or integrin complexes similar to those reported by Buck and co-workers (1986).
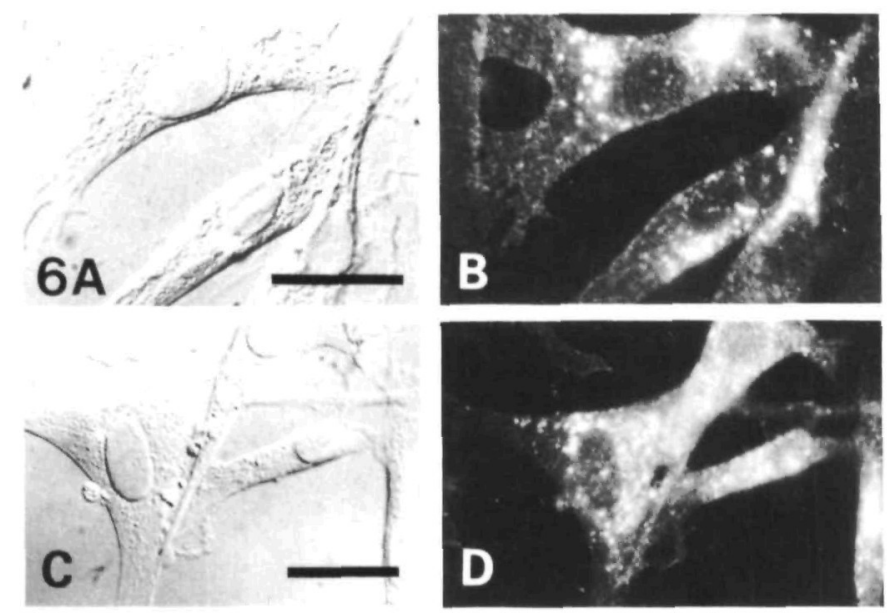

Fig. 6. CHF grown on planar substratum (glass) were stained with antibodies monospecific for CBP 1 . In A and B cells were fixed but not made permeable with detergent; $C$ and $\mathrm{D}$ show cells made permeable by treatment with Triton $\mathrm{X}-100$. When $\mathrm{CHF}$ were probed with antibodies monospecific for CBP 2 the staining pattern was identical to anti-CBP 1 immunostaining, in both the permeabilized and nonpermeabilized state (not shown). Bar, $20 \mu \mathrm{m}$.

\section{Discussion}

\section{Role of collagen binding proteins in substratum} adhesion

Antibodies to CBP inhibited the attachment and spreading of cells on collagen fibrils and caused the detachment of cells from untreated tissue-culture surfaces. Monospecific antibodies to CBP 1 and CBP 2 also caused retraction of cells from untreated planar substrata. In view of the apparent crossreactivity of the CBP antibodies with CSAT-purified avian integrins, and vice versa, it is likely that we prepared a 'generic' anti-integrin $\beta$ subunit antibody. Therefore, when anti-CBP is applied to embryonic chicken heart fibroblasts (CHF) grown on planar surfaces, all integrin-mediated extracellular matrix (ECM) adhesions are probably perturbed. In contrast, anti-CBP antibodies also inhibit cell attachment to a homogeneous scaffold of native collagen fibrils. This more specific inhibition activity suggests the presence of collagen integrins. Furthermore, it should be noted that the original immunogen was isolated on native collagen affinity colums (shown to be free of fibronectin).

The cell shape changes that occur concomitantly with antibody treatment show a perturbation of the actincontaining microfilament bundles. These observations also suggests the possibility that some of the collagen binding proteins may function similarly to integrins, by mediating concerted interactions between the cytoskeleton and the extracellular matrix (Chen et al. 1985; Horwitz et al. 1986; Burridge, 1986).

The recent observation of Fath et al. (1989) on the vitronectin integrin and fibronectin integrin shows that cells can redistribute their repertoire of receptors in response to a different ECM substratum. When cells were grown on planar substrata their integrins were localized to focal adhesions (Chen et al. 1985; Horwitz, 


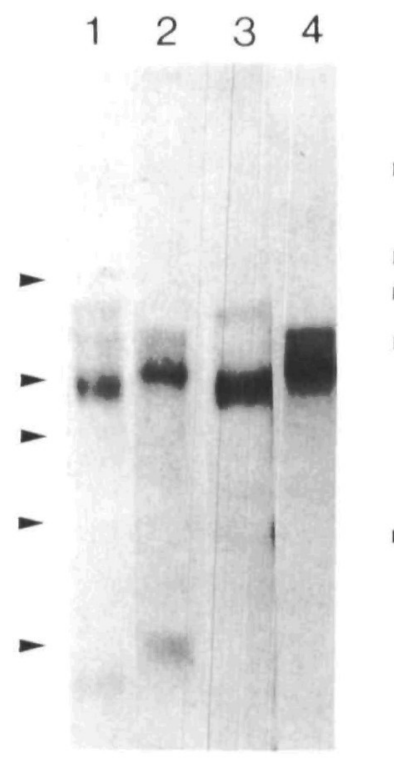

B

Integrin

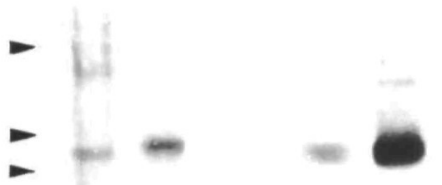

34

Fig. 7. A. Lysates prepared from cell-surface radioiodinated cultures were analyzed by immunoprecipitation using affinitypurified CBP antibodies (lanes 1 and 2) or $140 \mathrm{~K}$ antibodies (lanes 3 and 4). Similar electrophoretic patterns were observed: a major band of $100 \mathrm{~K}$ and less-prominent higher molecular weight bands were seen when samples were not reduced (lanes 1 and 3). Upon reduction with dithiothretol (lanes 2 and 4 ), the immunoreactive polypeptides ran as a diffuse heterogeneous band of approximately $120-140 \mathrm{~K}$. Arrowheads indicate the position of molecular weight markers (from the top: $205,116,97,66$ and $45 \mathrm{~K}$ ) after electrophoresis in this $5 \%$ to $10 \%$ gradient gel. B. Affinity-purified collagen binding proteins (collagen-Sepharose) and integrins purified by immunoaffinity (CSAT) chromatography were separated on $7.5 \%$ SDS-polyacrylamide slab gels, and then transferred to nylon membranes. Strips impregnated with CBPs were probed with $C B P$ antibodies (lane 1) or $140 \mathrm{~K}$ antibodies (lane 2). Other strips, impregnated with isolated integrins, were also probed with the anti-CBP (lane 3) or anti-140K serum (lane 4). All four lanes show an immunoreactive band at approximately $100 \mathrm{~K}$. Collagen binding proteins show higher molecular weight complexes when reacted with CBP antibodies (lane 1). Similarly, when CSAT-purified avian integrins are probed with anti-140K (lane 4), higher molecular weight complexes are recognized. The arrows denote the position of the same molecular weight markers described for $\mathrm{A}$.

1986; Burridge, 1986; Singer et al. 1988). In contrast, the CBP antibodies did not decorate focal adhesions on $\mathrm{CHF}$. Instead, a more dispersed labeling was observed for both the whole CBP antibody or the affinity-purified antibodies. One explanation for this lack of focal staining is that mature fibrillar collagen is not present in $\mathrm{CHF}$ focal adhesions on planar substrata.

In our experimental system, using three-dimensional fibrillar collagen gels, chicken embryo fibroblasts showed a fine granular staining distributed over the whole cell surface, including the finest protrusions observable by light microscopy. None of the cells showed immunofluorescent patterns characteristic of focal adhesions. Indeed,

under these more physiological conditions of growth, in a hydrated collagen lattice, embryonic fibroblasts do not form focal adhesions (Heath and Hedlund, 1984).

Previous immunostaining studies, using frozen sections of chicken embryos, showed that CBP was concentrated on the surface of cells adjacent to extracellular collagen I (Ogle et al. 1986). Attempts to extend the colocalization studies to whole mounts of cells within collagen gels in vitro were unsuccessful. Chicken embryo fibroblasts embedded in collagen fibrils did not stain with anti-CBP. The best explanation for this observation is that the antibodies were unable to bind to their antigenic sites due to steric hindrance by receptor-bound collagen fibrils.

After removal of collagen by collagenase the $\mathrm{CHF}$ surface showed strong immunoreactivity. In view of the fact that the cells shown in Fig. $5 \mathrm{C}$ and $\mathrm{D}$ were previously surrounded by a collagen lattice, it is noteworthy that the 'unmasked' CBPs are distributed in a granular pattern. The filopodia and protrusions of the 'liberated' cells show distinct punctate staining, with very dense immunolabelling in the perinuclear region. This latter distribution agrees with the findings of Heath and Hedlund (1984) on their studies of CHF locomotion in fibrillar collagen gels.

The total lack of detectable surface immunolabeling of cells within three-dimensional collagen gels, even at very high antibody concentration, leads to some interesting considerations. For instance, this is not the experimental result one would anticipate in view of the generic antiintegrin nature of the CBP antibody. This lack of surface staining suggests that when CHF are grown in a threedimensional ECM, the various integrins may be complexed in heterofunctional adhesion particles. We have no direct proof of this; however, if collagen receptors were distributed independently of other ECM receptors, one would not expect the presence of the collagen fibrils to hinder antibody access to all cell surface antigens. On the other hand, if most or all ECM receptors (integrins) were clustered in multifunctional attachment domains, then the saturating presence of a single ECM ligand (e.g. collagen fibrils) might then hinder immunolabeling of all the receptors in that particle.

As a positive control for these experiments, we showed that IgG could diffuse through the collagen gel and decorate intracellular tubulin, thus eliminating the possibility that antibodies did not have access to the CHF embedded within the hydrated collagen lattices.

\section{Relationship of CBP to integnins}

During the biochemical characterization of the CBP complex, it became evident that CBP 1 and CBP 2 shared properties with integrin subunits. These include: susceptibility to RGD peptide elution and molecular weight shift upon reduction when analyzed by SDS-PAGE (Ogle and Little, 1989).

Identification of the first avian integrin (see Buck and Horwitz, 1987) led to the determination of the protein structure of this receptor family (Tamkum et al. 1986). Human analogues to the avian integrin complex, have 
provided information on the function of these receptors and their relationships to each other (Hemler et al. 1987).

Our biochemical and functional analyses of avian collagen binding proteins suggests that these cell surface molecules are involved in mediating cell adhesion to collagen. We have compared affinity-purified CBP with the integrins through immunological cross-reactivity studies. Whole CBP antisera identified the $\beta$ subunit of immunopurified (CSAT) avian integrin complex. In addition, a polyclonal antisera $(140 \mathrm{~K})$, specific for the $\beta$ subunit of the avian integrin complex, identified a CBP at 100000 , the molecular weight of the avian $\beta$ subunit. Taken together, the biochemical and cell biological studies suggest that CBP 1 and CBP 2 are related to the avian integrin complex.

At the present time we can only speculate on the ligand specificity of CBPs 1 and 2. One possibility is that either polypeptide may be a subunit of a promiscuous integrin that recognizes multiple ECM components including collagen. Alternatively, or perhaps in addition, the molecules may represent a distinct collagen integrin that shares a $\beta$ subunit with other integrins. Either of these possibilities would result in immunological crossreactivity.

The platelet collagen receptor in mammals is an example of a well-characterized collagen integrin (Hemler et al. 1988; Kunicki et al. 1988; Takada et al. 1988). Our work suggests that, like humans, birds may have a collagen integrin. The exact nature of the $\alpha-\beta$ subunits responsible for mediating cell adhesion to collagen in avian embryos is under investigation.

This work was funded by grants to C.D.L. from the NSF program in Developmental Biology PGM-8215905 and a Basil O'Conner Starter Grant (5-465) from the March of Dimes Birth Defects Foundation. During these studies R.C.O. was supported by Developmental Biology Training Grant-T3HD07192. We thank Lydia Briscoe and Marian Hinson for assistance with manuscript preparation and Rebecca Ogle for photographic assistance.

\section{References}

AkiYama, S. K., YamadA, S. S. ANd YamadA, K. M. (1986) Characterization of a $140-\mathrm{kD}$ avian cell surface antigen as a fibronectin-binding molecule. f. Cell Biol. 102, 442-448.

Boudie, R. B., Horne, C. H. W. ANd Wilkinson, P. C. (1966). A simple method for producing antibody specific to a single selected diffusible antigen. Lancet ii, 1224-1226.

Buck, C. A. AND HorwTrz, A. F. (1987). Cell surface receptors for extracellular matrix molecules. A. Rev. Cell Biol. 3, 179-205.

Buck, C. A., Shea, E., Duggan, K. and Horwttz, A. F. (1986). Integrin (the CSAT antigen) functionality requires oligomeric integrity. 7. Cell Biol. 103, 2421-2428.

BurRIDGE, K. (1986). Substrate adhesions in normal and transformed fibroblasts, organization and regulation of cytoskeletal, membrane and extracellular matrix components at focal contacts. Cancer Rev. 4, 18-78.

Chen, J.-M. ANd LitTle C. D. (1985). Cells that emerge from embryonic explants produce fibers of type IV collagen. J. Cell Biol. $101,1175-1181$.

Chen, W.-T., Hasegawa, E., Hasegawa, T., Weinstock, C. and YamadA, K. M. (1985). Development of cell surface linkage complexes in cultured fibroblasts. 7. Cell Biol. 100, 1103-1114.

DeSimone, D. W. AND Hynes, R. O. (1988). Xenopus laevis integrins. J. bol. Chem. 263, 5333-5340.
Fath, K. R., Edgell, C.-J. S. And Burridge, K. (1989). The distribution of distinct integrins in focal contacts is determined by the substratum composition. $\}$. Cell Sci. 92, 67-75.

Greve, J. M. ANd GotTlieb, D. I. (1982). Monoclonal antıbodieg which alter the morphology of cultured chick myogenic cells, $\mathcal{J}$. cell Biochem. 18, 221-229.

Hay, E. D. (1984). Cell Biology of Extracellular Matrix. Plenum Press, New York, pp. 1-417.

Heath, J. P. ANd Hedlund, K.-O. (1984). Locomotion and cell surface movements of fibroblasts in fibrillar collagen gels. Scan Elect. Microsc. IV, 2031-2043.

Hemler, M. E., Crouse, C., Takada, Y. and Sonnenberg, A. (1988). Multiple very late antigen (VLA) heterodimers on platelets. F. biol. Chem. 263, 7660-7665

Hemler, M. E., Huang, C. and Schwartz, L. (1987). The VlaA protein family. 7. Biol. Chem. 262, 3300-3309.

Horwttz, A., Duggan, K., Buck, C., Beckerle, M. C. ANd BURRIDGE, K. (1986). Interaction of plasma membrane fibronectin receptor with talin-a transmembrane linkage. Nature, Lond. 320 , 531-533.

HYNES, R. O. (1987). Integrins: A family of cell surface receptors. Cell 48, 549-554.

Knudsen, K. A., Horwttz, A. F. AND Buck, C. A. (1985). A monoclonal antibody identifies a glycoprotein complex involved in cell-substratum adhesion. Expl. Cell Res. 157, 218-226.

Kunicki, T. J., Nugent, D. J., StaAts, S. J,, Orchekowski, R. P., Wayner, E. A. AND Carter, W. G. (1988). The human fibroblast class II extracellular matrix receptor mediates platelet adhesion to collagen and is identical to the platelet glycoprotein la-Ila complex. J. biol. Chem. 263, 4516-4519.

LAEMMLI, U. K. (1970). Cleavage of structural proteins during the assemble of the head of bacteriophage $\mathrm{T}_{4}$. Nature, Lond. 227 $860-865$.

LITTLE, C. D. AND CHEN, W.-T. (1982). Masking of extracellular collagen and the co-distribution of collagen and fibronectın during matrix formation by cultured embryonic fibroblasts. 7 . Cell Sci. $\mathbf{5 5}$ 35-50.

Marcantonio, E. E. and Hynes, R. O. (1988). Antibodies to the conserved cytoplasmic domain of the integrin $B_{1}$ subunit react wtih proteins in vertebrates, invertebrates and fungi. $\mathcal{F}$. Cell Biol. 106, 1765-1772.

Miller, E. J. AND Rhodes, R. R. (1982). Preparation and characterization of the different type of collagen. In Methods in Enzymology (L. W. Cunnıngham and A. W. Fredrickson, eds.), pp. 33-64. New York: Academic Press.

NefF, N. T., Lowrey, C., Decker, C., Tovar, A., Damskey, C., BuCK, C. ANd HorwtTz, A. F. (1982). A monoclonal antibody detaches embryonic skeletal muscle form extracellular matrices. $\mathcal{F}$ Cell Biol. 95, 654-666.

Ogle, R. C. ANd Little, C. D. (1989). Collagen binding proteins derived from the embryonic fibroblast cell surface recognize arginine-glycine-aspartic acid. Biosci. Rep. 9, 329-340

Ogle, R. C., Piquet, D. M. and Little, C. D. (1986). Collagen binding proteins associated with the chicken embryonic cell surface. Prog. clin. Biol. Res. 217B, 173-176.

Pytela, R., Pierschbacher, M. D. and Rouslahtr, E. (1985). Identification and solation of a $140 \mathrm{kDa}$ cell surface glycoprotein with properties expected of a fibronectin receptor. Cell $\mathbf{4 0}$, 191-198.

Rubin, K., Gullberg, D., Borg, T. K. And Obrink, B. (1986). Hepatocyte adhesion to collagen. Expl Cell Res. 164, 127-138.

Ruoslaht, E. and Pierschbacher, M. D. (1986). Arg-Gly-Asp: A versatile cell recognition signal. Cell 44, 517-518.

Schneider, C., Sutherland, R., Newman, R. and Greaves, $M$ (1982). Structural features of the cell surface receptor for transferrin that is recognized by the monoclonal antıbody OKT9. f. biol. Chem. 257, 8516-8527.

Singer, I. I., Scott, S., Kawka, D. W., Kazazis, D. M., Galeit, J. AND Rouslaht, E. (1988). Cell surface distribution of fibronectin and vitronectin receptors depends on substrate composition and extracellular matrix accumulation. 7 . Cell Biol 106, 2171-2182.

Takada, Y., Wayner, E. A., Carter, W. G. and Hemler, M. E. 
(1988). Extracellular matrix receptors, ECMRII and ECMRI, for collagen and fibronectin correspond to VLA- 2 and VLA-3 in the VLA family of heterodimers. 7. cell Biochem. 37, 385-393.

Talian, J. C., Olmsted, J. B. and Goldman, R. D. (1983). A rapid procedure for preparing fluorescein-labeled specific antibodies from whole antiserum, its use in analysizing cytoskeletal architecture. 7. Cell. Biol. 97, 1277-1282.

Tamkum, J. W., DeSimone, D. W., Fonda, D., Patel, R. S., Buck, C., HORWITZ, A. F. AND HyNes, R. O. (1986). Structure of
Integrin, a glycoprotein involved in the transmembrane linkage between fibronectin and actin. Cell 46, 271-282.

Tomasek, J. J. AND HaY, E. D. (1984). Analysis of the role of microfilaments and microtubules in acquisition of bipolarity and elongation of fibroblasts in hydrated collagen gels. J. Cell Biol. 99 536-549.

(Received 24 February 1989 - Accepted, "' revised form, 11 guly 1989) 
